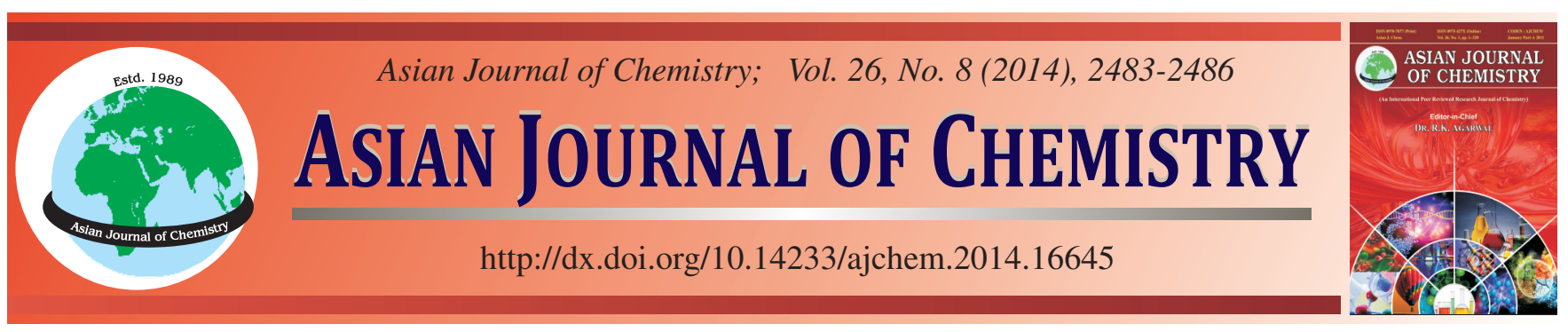

\title{
Determination of Chromium(III) in Real Samples by Flame Atomic Absorption Spectrometry with Cloud Point Extraction Using Tergitol TMN-6
}

\author{
LIFEN MENG ${ }^{1}$, JiNYAN Ning ${ }^{1}, \mathrm{~J}_{\mathrm{iAO}} \mathrm{ZHAO}^{1}$ and $\mathrm{Li} \mathrm{BI}^{2, *}$
}

${ }^{1}$ Faculty of Life Science and Technology, Kunming University of Science and Technology, Kunming 650500, Yunnan Province, P.R. China ${ }^{2}$ College of Science, Kunming University of Science and Technology, Kunming 650500, Yunnan Province, P.R. China

*Corresponding author: E-mail: libzty1990@163.com; 1025588702@qq.com

Received: 6 November 2013;

Accepted: 31 December 2013;

Published online: 15 April 2014;

AJC-15054

\begin{abstract}
A rapid and selective cloud point extraction based on tergitol TMN-6 has been used for determination of chromium ion. 8-Hydroxyquinoline (oxine) was used as a selective complexing agent to form stable Cr-oxine complex which can be extracted with TMN-6 at a short time and its determination using flame atomic absorption spectrometry (FAAS). Several variables such as sample $\mathrm{pH}$, concentration of oxine and salt, equilibration temperature and time, the effect of foreign ions were evaluated in order to enhance sensitivity of the method. Under the optimum conditions, the limit of detection (LOD) was $2.9 \mu \mathrm{g} \mathrm{L}^{-1}$ and relative standard deviation (RSD \%) was $4.2 \%(\mathrm{n}=11$ ). The cloud point extraction method has been shown to be a potentially useful methodology for the preconcentration of the target analytes, with a preconcentration factor of 20 . The high recoveries of the spiked $\mathrm{Cr}(\mathrm{III})$ ions were obtained in the range $90-108 \%$. This method was compared with cloud point extraction (using Triton X-114) and liquid-liquid microextraction (using ionic liquid).
\end{abstract}

Keywords: Cloud point extraction, 8-Hydroxyquinoline, Chromium, Flame atomic absorption spectrometry, Tergitol TMN-6.

ᄂ - - - - - - - - - - - - - - - - - - - - - - - - -

\section{INTRODUCTION}

In the environment, chromium occurs mainly in the oxidation states (III) and (VI). The Cr(III) is essential for plants and animals at trace concentrations, whereas $\mathrm{Cr}(\mathrm{VI})$ is considered to be a more toxic form because of its high oxidizing potential. Recently, extensive use of chromium in industrial processes has led to discharged large quantities of chromium into the environment, leading to serious problems and hazardous risks for the human health.

The separation/preconcentration methods for determination of chromium reported in literature include: coprecipitation $^{1}$, solvent extraction and solid phase extraction ${ }^{2,3}$, ion exchange separation ${ }^{1,4}$, electrochemical methods ${ }^{5}$, high performance liquid chromatography ${ }^{6}$, ion chromatography ${ }^{7}$ and capillary electrophoresis ${ }^{8}$. However, most of the methods mentioned above are often complicated and time consuming or have high operation costs. Thus, a simple and efficient separation technique for chromium species is essential.

Cloud point extraction has attracted a lot of attention as an alternative to traditional liquid-liquid extraction. The cloud point extraction was first introduced by watanabe and others in $1976^{9}$. Cloud point of the aqueous solutions of surfactant micellar systems is a temperature at which the solution becomes turbid before separating into two phases, a surfactant-rich phase and an aqueous phase. The surfactant rich phase is able to extract and preconcentrate analytes. The cloud point extraction methodology is based on surfactant-mediated phase separation. During the cloud point extraction procedure, targets can be successfully extracted and preconcentrated by changing the conditions affecting phase separation in a single step; the preconcentration factor can reach more than 10. Importantly, in cloud point extraction, the surfactants are less toxic, cheaper and more environment friendly than the organic solvents. For the aforementioned advantages, cloud point extraction has been successfully used for the preconcentration of species of widely differing characteristics as a previous step to their later determination by HPLC ${ }^{10,11}$, gas chromatography $(\mathrm{GC})^{12-15}$ and atomic absorption spectrometry ${ }^{16-18}$.

TMN-6 is polyethylene glycol trimethylnonyl ether, a nonionic surfactant, with no aromatic group, which excellent biodegradability and environment-friendly and its cloud point (CP) is about $55^{\circ} \mathrm{C}$.

In this research, TMN-6 was studied as the cloud point extractant in the preconcentration and treatment of the $\mathrm{Cr}$ (III) ions by FAAS. Compared with Triton X-114, a much higher enrichment factor was obtained by the cloud point extraction system with TMN-6 under the condition of the same total surfactant concentration. Different experimental conditions were studied to determine the optimal condition for the analysis of the real samples. 
EXPERIMENTAL

A vortex instrument was employed for the cloud point experiments (Shanghai, China) and flame atomic absorption spectrometer (AA-6300C, Shimadzu, Japan) was used for the determination of the concentration of metal. A centrifuge (Shanghai, China) was used to completed the phase separation process.

All the reagents used were of analytical reagent grade and all solutions were prepared in deionized water. A stock standard solution of chromium at a concentration of $1000 \mu \mathrm{g}$ $\mathrm{mL}^{-1}$ was obtained from the National Institute of Standards (Beijing, China), Tergitol TMN-6 and 8-hydroxyquinoline (Aladdin, China) were used.

Cloud point extraction procedure: For the cloud point extraction experiments, aliquots of working standard solution of $\mathrm{Cr}(\mathrm{pH}=9), 0.5 \mu \mathrm{g} \mathrm{L}^{-1}$ oxine $(200 \mu \mathrm{L}), 100 \mu \mathrm{L}$ TMN-6 and $0.2 \mathrm{~g}\left(\mathrm{NH}_{4}\right)_{2} \mathrm{SO}_{4}$ were placed in a $10 \mathrm{~mL}$ screw cap glass centrifuge tube with conical bottom. Then, the glass centrifuge tube was vortex-mixed for $2 \mathrm{~min}$. The mixtures were diluted to $5 \mathrm{~mL}$ with deionized water. Then, the glass centrifuge tube was put in the water-bath at $55^{\circ} \mathrm{C}$ for $15 \mathrm{~min}$. The cloudy solution was separated by centrifugation at $3000 \mathrm{rpm}$ for $10 \mathrm{~min}$. After phase separation, the aqueous phase was then removed from the centrifuge tube by a syringe. The surfactant rich phase was diluted with deionized water to $1 \mathrm{~mL}$ and then the analyte contents were determined by flame atomic absorption spectroscopy.

\section{RESULTS AND DISCUSSION}

Effect of $\mathbf{p H}$ on cloud point extraction: $\mathrm{pH}$ Plays a unique role on metal-chelate formation and subsequent extraction. In order to evaluate the effect of $\mathrm{pH}$ on the extraction efficiency of $\mathrm{Cr}$ (III), the $\mathrm{pH}$ values of sample solutions was studied in the range of 5-13 and the results are shown in Fig. 1. According to the results, the absorbance was nearly constant in the $\mathrm{pH}$ range of 8-13 for $\mathrm{Cr}$ (III) and hence, $\mathrm{pH} 9$ was chosen as the optimum value.

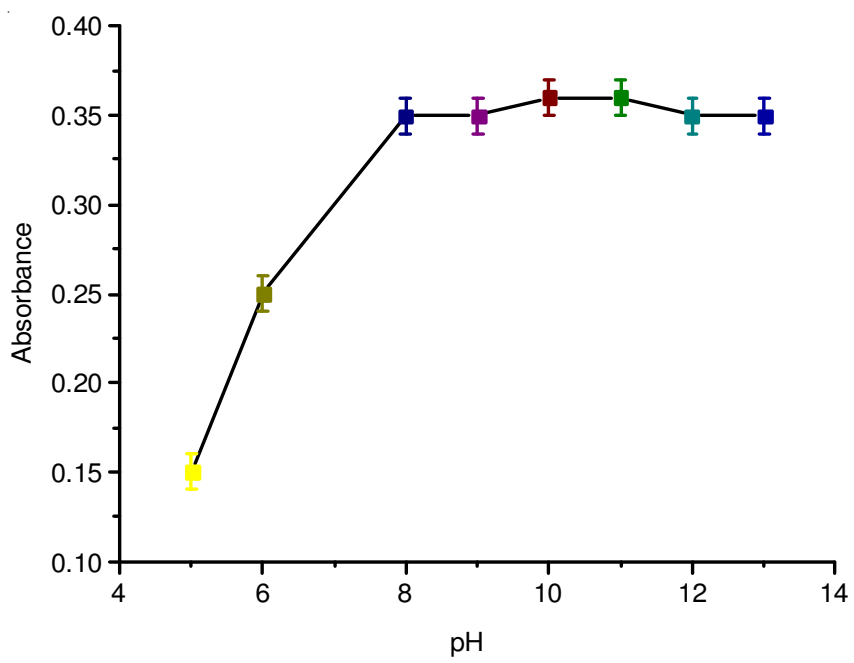

Fig. 1. Effect of $\mathrm{pH}$ on the cloud point extraction

Effect of oxine concentration: The extraction efficiency depends on the hydrophobicity of the ligand that influence the hydrophobicity of the complex, the kinetics of the chelate formation, the apparent equilibrium constants in the TMN-6 medium and the partition coefficients. In this work, 8-hydroxyquinoline (oxine) was used as the chelating agent due to the highly hydrophobic nature of its metal chelates. Concentration of chelating agent is a critical variable and, it is highly important to establish the minimal reagent concentration that leads to total complex formation while achieving the highest extraction. The effect of concentration of oxine was investigated in the range of 0.1 to $2 \mu \mathrm{g} \mathrm{L}^{-1}$. The results are given in Fig. 2 and show that the absorbance increased by increasing the oxine concentration up to $0.5 \mu \mathrm{g} \mathrm{\textrm {L } ^ { - 1 }}$ and then remained constant afterwards. A concentration of $0.5 \mu \mathrm{g} \mathrm{L}^{-1}$ of oxine was chosen for subsequent determinations.

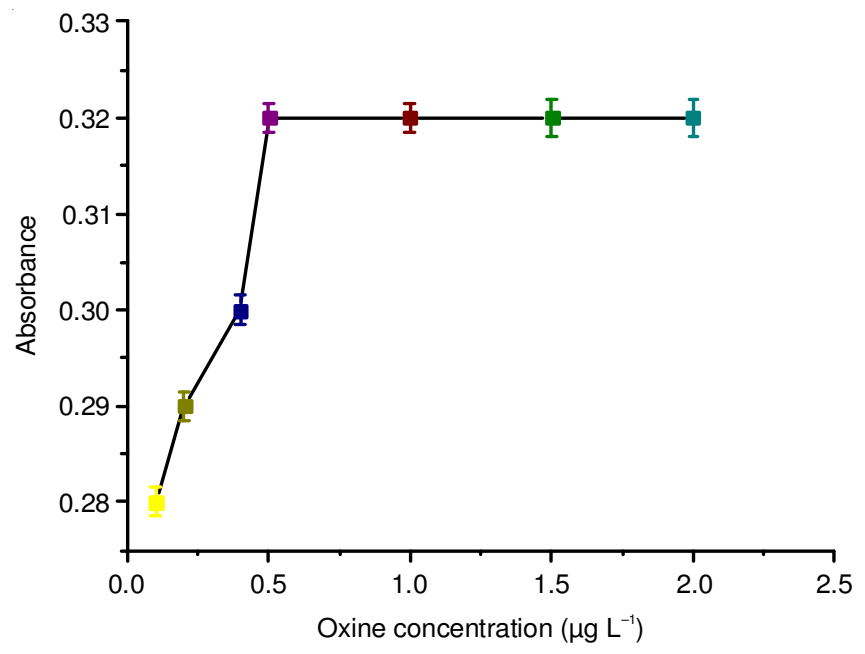

Fig. 2. Effect of oxine concentration on the cloud point extraction

Effect of temperature and time on cloud point extraction: When the cloud point extraction procedure was processed at the equilibration temperature of the surfactant, the best extraction efficiency was achieved. A temperature range of $35-60{ }^{\circ} \mathrm{C}$ was studied. Maximum extraction efficiency was observed in the range of $50-60{ }^{\circ} \mathrm{C}$; beyond $60^{\circ} \mathrm{C}$, a little decrease of the efficiency was obtained. Accordingly, $55{ }^{\circ} \mathrm{C}$ was used in the cloud point extraction procedure. The equilibration time was also investigated in the range of 5-60 min. It was found that the maximum extraction efficiency was presented between 15 and $20 \mathrm{~min}$. Therefore, $15 \mathrm{~min}$ was chosen as the optimum equilibration time.

Effects of foreign ions: In order to demonstrate the selectivity of the developed cloud point extraction system, the effect of other ions on $\mathrm{Cr}$ ions determination was evaluated. The interferences were studied by analyzing $5 \mathrm{~mL}$ solution containing $2 \mu \mathrm{g} \mathrm{mL}^{-1} \mathrm{Cr}$ (III). An ion was considered to interfere when its presence produced a variation of more than $5 \%$ in the absorbance of the sample. The results are shown in Table- 1. As it is shown, the recovery is quantitative and satisfactory in the presence of most foreign cations and the major cations in the real samples have no obvious influence on cloud point extraction of $\mathrm{Cr}$ (III) ion under the selected conditions.

Comparison with Triton X-114 cloud point extraction and LLME (Using ionic liquid): Different surfactants and extracting agents demonstrate different efficiencies of 


\begin{tabular}{ccc}
\hline \multicolumn{3}{c}{ TABLE-1 } \\
\multicolumn{3}{c}{$\begin{array}{c}\text { EFFECT OF DIVERSE IONS ON THE } \\
\text { DETERMINATION OF CHROMIUM(II) }\end{array}$} \\
\hline Coexisting ions & $\begin{array}{c}\text { Molar ratio } \\
\text { (ion/chromium) }\end{array}$ & Recovery (\%) \\
\hline $\mathrm{Cl}^{-}$ & 3000 & 99 \\
$\mathrm{PO}_{4}{ }^{3-}, \mathrm{NO}_{3}{ }^{-}$ & 1800 & 98.4 \\
$\mathrm{SO}_{4}{ }^{2-}$ & 1000 & 97.5 \\
$\mathrm{Na}^{+}$ & 4000 & 101.8 \\
$\mathrm{~K}^{+}$ & 3000 & 97.3 \\
$\mathrm{Co}^{2+}$ & 2000 & 98 \\
$\mathrm{Cd}^{2+}, \mathrm{Mn}^{2+}$ & 1800 & 96 \\
$\mathrm{Ca}^{2+}$ & 1500 & 97.2 \\
$\mathrm{~Pb}^{2+}$ & 50 & 98.3 \\
$\mathrm{Fe}^{2+}$ & 20 & 96 \\
$\mathrm{Zn}^{2+}$ & 10 & 96 \\
$\mathrm{Cu}^{2+}$ & 10 & 96.8 \\
$\mathrm{Ni}^{2+}$ & 10 & 97 \\
\hline
\end{tabular}

extraction for certain targets based on various factors. Thus, the most commonly used surfactant, Triton X-114 ${ }^{10}$, in cloud point extraction and extracting agent, ionic liquid, were selected to compare with TMN-6 cloud point extraction method performance. The remaining results are shown in Fig. 3. TMN6 had an advantage over Triton X-114-CPE and ionic liquidLLME in terms of recovery.

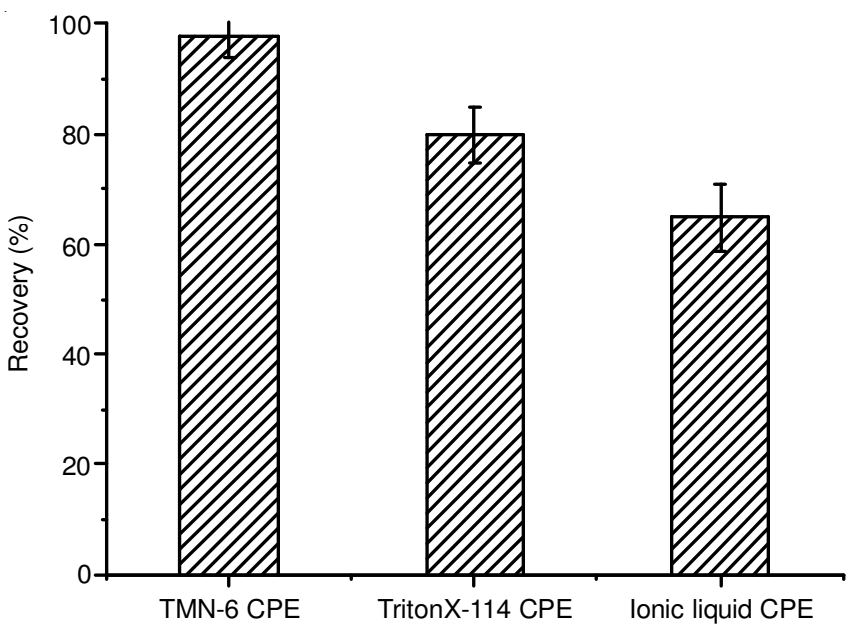

Fig. 3. Comparison of TMN-6 cloud point extraction with TritonX-114 cloud point extraction and LLME- Ionic liquid in terms of recovery

Analytical characteristics: The analytical characteristics of the method were evaluated under the optimum experimental conditions. The enrichment factor (EF), relative standard deviations and limits of detection are effective factors to evaluate a developed analytical method. With the optimized system, the calibration graph of $\mathrm{Cr}$ was linear in the range of $10-500 \mu \mathrm{g} \mathrm{L}^{-1}$. The calibration equation is $\mathrm{A}=1.0 \times 10^{-3} \mathrm{C}-0.0061$ with a correlation coefficient of 0.9981 , where $\mathrm{A}$ is the absorbance and $\mathrm{C}$ is the $\mathrm{Cr}$ concentration in $\mu \mathrm{g} \mathrm{L}^{-1}$. The detection limits, defined as the concentration equivalent to three times the standard deviation $(n=11)$ of the reagent blank was $2.9 \mu \mathrm{g} \mathrm{L}^{-1}$. The relative standard deviation for $\mathrm{Cr}$ was $4.2 \%$. The enhancement factor, defined as the ratio of slope of preconcentrated samples to that obtained without preconcentration, was 20.
Analysis of real samples: The recommended procedure was examined to determine $\mathrm{Cr}$ (III) ion in real samples including tap water, spring water and seawater, which were all from Luolong river, Kunming. And all the water samples are spiked with $\mathrm{Cr}$ (III) standard solution at different concentration levels to assess the matrix effects. The results are shown in Table- 2 . It shows that the developed method applied to the determination of $\mathrm{Cr}$ (III) in real samples.

\begin{tabular}{|c|c|c|c|}
\hline \multicolumn{4}{|c|}{$\begin{array}{c}\text { TABLE-2 } \\
\text { RESULTS OF DETERMINATION } \\
\text { OF CHROMIUM IN REAL SAMPLES }\end{array}$} \\
\hline Sample & Spiked $\left(\mu \mathrm{g} \mathrm{L}^{-1}\right)$ & Found $\left(\mu \mathrm{g} \mathrm{L}^{-1}\right)$ & Recovery (\%) \\
\hline \multirow{3}{*}{ Tap water } & 0 & Not detected & - \\
\hline & 20 & $20.7 \pm 0.4$ & 103.5 \\
\hline & 50 & $54.4 \pm 0.9$ & 108.8 \\
\hline \multirow{3}{*}{ Spring water } & 0 & Not detected & - \\
\hline & 20 & $19.9 \pm 0.5$ & 99.5 \\
\hline & 50 & $51.2 \pm 0.9$ & 102.4 \\
\hline \multirow{3}{*}{ Sea water } & 0 & Not detected & - \\
\hline & 20 & $18.7 \pm 0.4$ & 93.5 \\
\hline & 50 & $50.0 \pm 1.0$ & 100 \\
\hline
\end{tabular}

Comparison of Tergitol TMN-6 with other reported reagents: Table- 3 compares the characteristic data of the tergitol TMN-6 with other reported reagents for the determination of $\mathrm{Cr}$ (III) in literature. As it can be seen, the proposed method possesses lower limit of detection and preconcentration time than most reported reagentas with only $5 \mathrm{~mL}$ of the sample solution and is suitable for determination of trace amounts of $\mathrm{Cr}(\mathrm{III})$ in real samples. The type of samples and matrix doesn't affect the determination of $\mathrm{Cr}$ (III).

\begin{tabular}{lcccccc}
\multicolumn{7}{c}{ TABLE-3 } \\
\multicolumn{7}{c}{$\begin{array}{c}\text { COMPARISON OF TERGITOL TMN-6 } \\
\text { WITH OTHER REPORTED REAGENTS }\end{array}$} \\
\hline \multirow{2}{*}{ Reagent } & $\begin{array}{c}\text { Sample } \\
\text { volume } \\
(\mathrm{mL})\end{array}$ & $\begin{array}{c}\text { Precon- } \\
\text { centration } \\
\text { time }(\mathrm{min})\end{array}$ & $\begin{array}{c}\text { RSD }(\%) \\
(\mathrm{n}=9)\end{array}$ & $\begin{array}{c}\text { Injection } \\
\text { volume } \\
(\mathrm{mL})\end{array}$ & $\begin{array}{c}\text { LOD } \\
(\mu \mathrm{g} / \mathrm{L})\end{array}$ & Ref. \\
\hline TritonX-114 & 10 & $>15$ & 2.7 & 0.5 & 7.5 & 19 \\
CTAB & 10 & 12 & 2.2 & 0.5 & 12 & 20 \\
TritonX-100 & 10 & $>15$ & 2.1 & 5 & 6.5 & 21 \\
Tergitol & 5 & 10 & 4.2 & 0.1 & 2.9 & $\begin{array}{c}\text { This } \\
\text { paper }\end{array}$ \\
TMN-6 & & & & & & \\
\hline
\end{tabular}

\section{Conclusion}

A simple, sensitive and reliable cloud point extraction methodology has been established in the present work. Tergitol TMN-6 as a non-ionic surfactant was used in the process of cloud point extraction with a good enrichment factor and low LOD. The proposed method was successfully applied for the determination of trace $\mathrm{Cr}$ (III) in real samples.

\section{ACKNOWLEDGEMENTS}

The authors are very grateful for financial support by the Yunnan Provincial Department of Education (NO. 2012Z018) and Innovation Fund for Small and Medium Technology Based Firms (No. 11C26215305946). 


\section{REFERENCES}

1. L. Wang, B. Hu, Z. Jiang and Z. Li, Int. J. Environ. Anal. Chem., 82, 387 (2002).

2. P. Liang, C. Li, Y. Qin, B. Hu and Z. Jiang, Fenxi Kexue Xuebao, 16, 300 (2000).

3. D. Adria-Cerezo, Talanta, 51, 531 (2000).

4. E. Menendez-Alonso, S.J. Hill, M.E. Foulkes and J.S. Crighton, J. Anal. At. Spectrom., 14, 187 (1999).

5. M.J. Schick, Non-ionic Surfactants, Marcel Dekker, New York (1987).

6. K.L. Mittal, Solution Chemistry of Surfactants, Plenum, New York (1979).

7. M. Arbab-Zavar, Talanta, 52, 1007 (2000).

8. H.H. Willard and P. Young, J. Am. Chem. Soc., 51, 149 (1929).

9. J. Miura, H. Ishii and H. Watanabe, Bunseki Kagaku, 25, 808 (1976).

10. M. Chen, Q. Xia, M. Liu and Y. Yang, J. Food Sci., 76, C98 (2011).

11. W. Zhang, C. Duan and M. Wang, Food Chem., 126, 779 (2011).
12. J.C. Shen and X.G. Shao, Anal. Chim. Acta, 561, 83 (2006).

13. T.I. Sikalos and E.K. Paleologos, Anal. Chem., 77, 2544 (2005).

14. A. Ohashi, M. Ogiwara, R. Ikeda, H. Okada and K. Ohashi, Anal. Sci., 20, 1353 (2004).

15. G.F. Jia, C.G. Lv, W.T. Zhu, J. Qiu, X.Q. Wang and Z.Q. Zhou, J. Hazard. Mater., 159, 300 (2008).

16. H.I. Ulusoy, M. Akcay, S. Ulusoy and R. Gurkan, Anal. Chim. Acta, 703, 137 (2011).

17. N.F. Kolachi, T.G. Kazi, S. Khan, S.K. Wadhwa, J.A. Baig, H.I. Afridi, A.Q. Shah and F. Shah, Food Chem. Toxicol., 49, 2548 (2011).

18. F. Shah, T.G. Kazi, H.I. Afridi, Naeemullah, M.B. Arain and J.A. Baig, J. Hazard. Mater., 192, 1132 (2011).

19. L.-L. Wang, J.-Q. Wang, Z.-X. Zheng and P. Xiao, J. Hazard. Mater., 177, 114 (2010).

20. M. Hashemi and S.M. Daryanavard, Spectrochim. Acta A, 92, 189 (2012).

21. X. Zhu, B. Hu and Z. Jiang, J. Environ. Anal. Chem., 84, 927 (2004). 